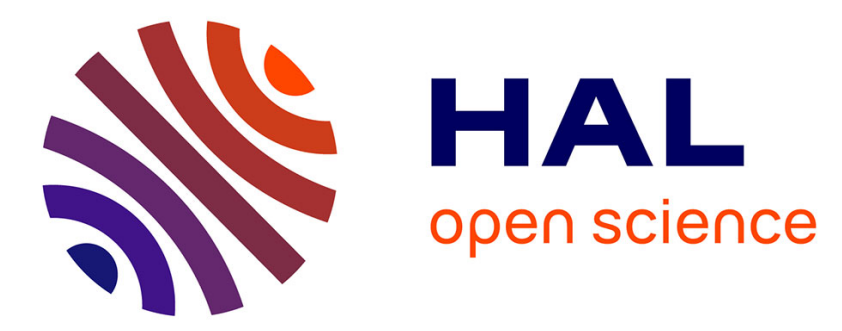

\title{
Intersexuality incidence, sex ratio fluctuations and intersex reproductive output as factors affecting the temporal variation of intersexed populations of the marine amphipod
}

\author{
Irene Martins, Alex T. Ford, Teresa F. Fernandes
}

\section{To cite this version:}

Irene Martins, Alex T. Ford, Teresa F. Fernandes. Intersexuality incidence, sex ratio fluctuations and intersex reproductive output as factors affecting the temporal variation of intersexed populations of the marine amphipod. Marine Environmental Research, 2009, 68 (4), pp.163. 10.1016/j.marenvres.2009.06.007 . hal-00505737

\section{HAL Id: hal-00505737 \\ https://hal.science/hal-00505737}

Submitted on 26 Jul 2010

HAL is a multi-disciplinary open access archive for the deposit and dissemination of scientific research documents, whether they are published or not. The documents may come from teaching and research institutions in France or abroad, or from public or private research centers.
L'archive ouverte pluridisciplinaire HAL, est destinée au dépôt et à la diffusion de documents scientifiques de niveau recherche, publiés ou non, émanant des établissements d'enseignement et de recherche français ou étrangers, des laboratoires publics ou privés. 


\section{Accepted Manuscript}

Intersexuality incidence, sex ratio fluctuations and intersex reproductive output as factors affecting the temporal variation of intersexed populations of the marine amphipod Echinogammarus marinus

Irene Martins, Alex T. Ford, Teresa F. Fernandes

PII:

S0141-1136(09)00066-X

DOI:

10.1016/j.marenvres.2009.06.007

Reference:

MERE 3343

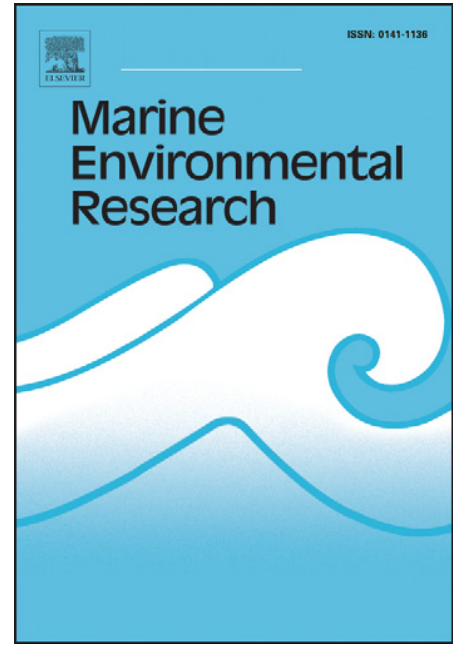

To appear in:

Marine Environmental Research

Received Date:

14 February 2008

Revised Date:

17 March 2009

Accepted Date:

2 June 2009

Please cite this article as: Martins, I., Ford, A.T., Fernandes, T.F., Intersexuality incidence, sex ratio fluctuations and intersex reproductive output as factors affecting the temporal variation of intersexed populations of the marine amphipod Echinogammarus marinus, Marine Environmental Research (2009), doi: 10.1016/j.marenvres. 2009.06.007

This is a PDF file of an unedited manuscript that has been accepted for publication. As a service to our customers we are providing this early version of the manuscript. The manuscript will undergo copyediting, typesetting, and review of the resulting proof before it is published in its final form. Please note that during the production process errors may be discovered which could affect the content, and all legal disclaimers that apply to the journal pertain. 
Intersexuality incidence, sex ratio fluctuations and intersex reproductive output as factors affecting the temporal variation of intersexed populations of the marine amphipod Echinogammarus marinus

Irene Martins $^{1 *}$, Alex T. Ford ${ }^{2}$, Teresa F. Fernandes ${ }^{3}$

1- IMAR-Institute of Marine Research, Coimbra Interdisciplinary Centre, Department of Zoology, University of Coimbra, 3004-517 Coimbra, Portugal.

2- School of Biological Sciences, University of Portsmouth, King Henry Building, Portsmouth, PO1 2DT, England, UK.

3- School of Life Sciences, Napier University, 10 Colinton Road, Edinburgh EH10 5DT, Scotland, UK. *Corresponding author: Tel. +351 239855760 ext. 415; Fax. +351 239 823603; Email: imartins@ci.uc.pt

\begin{abstract}
The occurrence of intersexuality in populations of the marine amphipod Echinogammarus marinus has been related to several causes, including anthropogenic contamination, microsporidian parasites and environmental sex determination (ESD). At the individual level, the costs of intersexuality in E. marinus are reflected in reduced reproductive output of intersexes compared to normal specimens. To understand the consequences of intersexuality at the population level is essential to fully evaluate the impacts of intersexuality and other reproductive disorders in nature. The aim of the present work is to simulate the density variation of real populations of E. marinus with different intersexuality incidence, proportions of phenotypes and intersex female reproductive rates. To achieve that, we have incorporated empirical data from three intersexed populations of E. marinus into a population dynamic model. The original model
\end{abstract}


was calibrated and validated for a stable population without intersexuality and sex ratio $\sim 1$. In the present version, the model includes an extra group, intersex females, but the total sum of flow rates from juveniles to adult groups was kept the same as in the original model to respect the previous validation. In these circumstances, results indicate that the male-biased population is very sensitive to intersexuality, even at low incidence levels, and exhibits significant density decrease through time if conditions do not change. On the contrary, the two E. marinus populations with a preponderance of female-biased sex ratios, low or moderate intersexuality incidence (up to an average value of $9 \%$ of the population) and with intersex reproductive rates corresponding to $80 \%$ the value of normal specimens, exhibit long-term persistence.

The model is highly sensitive to adult female parameters (e.g. mortality), indicating that small variations on its values can significantly change population responses.

Overall the present results suggest that, in spite the costs of intersexuality in E. marinus, the temporal variation of intersexed populations seems to depend on intersex incidence level, sex ratio fluctuations and reproductive output of intersexes. Simulations also suggest that other population processes (e.g. mortality rates of normal females) may play important roles in the maintenance of populations with intersexuality.

Key-words: amphipod, intersexuality, reproductive disorders, reduced fitness, sex ratio, population-level effects, mathematical model

\section{Introduction}

Intersexuality is the occurrence, in dioecous species, of individuals that possess both male and female sexual characteristics (Kelly et al., 2004). The causes of intersexuality in Crustacea are not yet fully understood but they seem to be due to different factors, such as chemical contamination (e.g. Takahashi et al., 2000; Olmstead and Leblanc, 2007), incomplete feminisation caused by microsporidian parasites (Kelly et al., 2002) or environmental sex 
determination (ESD) (Dunn et al., 1996, 2005). In a recent study carried out at distinct places in relation to environmental quality, Ford et al. (2006) suggested that, at anthropogenic impacted sites, the probable cause of intersexuality was parasitism, which seem to be enhanced by pollution, while ESD was suggested as the possible cause of intersexuality at the reference locations. Although the causes of intersexuality seem multi-factorial and complex to determine, the decreased reproductive fitness of intersexes is a well-known consequence in several species (Jobling et al., 2002; Kelly et al., 2004). Intersex individuals of E. marinus suffer from reduced fecundity and fertility and mature at a larger size compared to normal specimens (Ford et al., 2003; 2004b). It has also been suggested that the increased size and morphological abnormalities of intersexes may result in reduced pairing success (Kelly et al., 2004; Ford et al., 2004). Thus, accordingly to the sex allocation theory (Charnov, 1982), intersexes should be selected against, which is somehow contradictory with the frequent finding of intersexes in some natural populations (Ford and Glazier, 2008). This suggests that other processes are involved and confirms our limited knowledge of the consequences of intersexuality and the underlying processes.

Population dynamic models are suitable tools to incorporate individual fitness costs and assess effects at the population level (Martins et al., 2002). This approach has been previously applied to intersexed populations of E. marinus (Ford et al., 2007) and aimed to assess the effects of varying levels of intersexuality and phenotypes on population response. Although this work was important, as it was one of the first attempts to extrapolate individual-level effects to the population-level, it relied on theoretical values of intersexuality incidence, normal and intersex phenotypes proportions with a consequent narrow practical application.

The aim of the present work is to simulate the density variation of real populations of E. marinus with different intersexuality incidence, proportions of phenotypes and intersex female reproductive rates. To achieve that, we have incorporated empirical data from three intersexed populations of E. marinus into a population dynamic model. It is expected that results from this 
type of approach will help us to understand the mid- to long-term consequences of intersexuality in natural populations.

\section{Materials and Methods}

\subsection{Model description}

The model used in this study is based on a previously calibrated and validated model for a population of E. marinus with long-term stability, average sex ratio of 1 and without intersexuality (Martins et al., 2002). The new version of the model incorporates intersex females into the original structure of the model (Fig. 1) and accounts for phenotype variations (i.e. proportion of normal males, normal females and intersex females) in accordance to values obtained for three different Scottish populations between spring 2002 and spring 2003.

Model state variables are juveniles, immature females, adult females, intersex females and males in abundance (number of individuals $\mathrm{m}^{-2}$ ). Intersex males were not included in the model because 1) in the considered populations, intersex males correspond only to $3 \%$ of the population and 2) empirical values of the costs of intersexuality in males are difficult to obtain.

The model accounts for growth and mortality of all population groups and reproduction of females. Due to lack of empirical data, the mortality rate of intersex females was considered equal to the mortality rate of normal females.

The weight of females is also accounted in the model because female reproduction rate depends on their size. Female's weight is calculated on a dynamic way through the biomass calculation module of the model (Martins et al., 2002), which follows a modified Von Bertalanffy (1957) model and accounts for a temperature regulating factor (Table 1). At each sampling site, the reproduction rate of intersex females was obtained in relation to the reproduction rate of normal females, which was accounted in the model. 


\subsection{Data sets}

Data sets used to extract the parameters to incorporate into the model were obtained between spring 2002 and spring 2003, at three sampling sites within the Firth of Forth (Scotland): Dunbar, Torry Bay and Inverkeithing Bay (Ford et al., 2006). Sex ratio was calculated as the number of males by the total number of females (normal and intersex females).

The population of E. marinus at Dunbar exhibited the lowest incidence of intersex females corresponding to $5.4 \% \pm 1.8$ (average \pm standard deviation) and, during the sampling period, this population was always male-biased, with normal females representing less than $41 \%$ of the population. As a consequence, this population exhibited the highest sex ratios, ranging from 1.1 to 1.6 (Fig. 2). Intersex females presented, on average, $11.9 \%$ less reproductive output than normal females (extrapolated from Ford, 2004).

E. marinus population at Torry Bay exhibited a proportion of intersex females corresponding to $7.2 \% \pm 3$ of the population and the population was always female-biased, with sex ratios ranging between 0.29 and 0.84 (Fig. 2). Intersex females presented about $21.6 \%$ less reproductive output than normal females (extrapolated from Ford, 2004).

The incidence of female intersexuality was the highest at Inverkeithing Bay, corresponding to $9.2 \% \pm 5.2$ of the population and, except during winter, the population was always female-biased with a sex ratio variation between 0.32 and 1.19 (Fig. 2). Intersex females showed 19\% less reproductive output than normal females (extrapolated from Ford, 2004).

\subsection{Re-calibration and sensitivity analysis}

In the original model, the flow units between population groups, corresponding to number of individuals $\mathrm{m}^{-2} \mathrm{~d}^{-1}$, were calibrated in accordance to original empirical data (Maranhão et al., 2001; Maranhão and Marques, 2003). In the present version of the model, these parameters were re-calibrated until the proportion of phenotypes output by the model matched the observed proportion of phenotypes at each one of the three sampling sites (Table 2), corresponding to 
three different re-calibrations according to phenotype variation observed at Dunbar, Torry Bay and Inverkeithing Bay, respectively.

The present version of the model includes one extra state variable than the original version, corresponding to intersex females. Consequently, this version also includes one extra flow between groups corresponding to the flow of individuals from immature females to intersex females ( $t 4$ in Fig. 1). Nevertheless, to keep the balance of the present version in accordance to the original validation, the total sum of flow rates between population groups was kept equal to the original version of the model.

Long-term scenarios $(\sim 5$ years $)$ of the three studied populations assumed that, for the entire simulation period, the populations exhibited the same seasonal phenotype variation, intersexuality incidence and reproductive rates as observed within the studied periods at Dunbar, Torry Bay and Inverkeithing Bay. The variation of intersexuality incidence and sex ratio used to force the model at the three simulated scenarios is shown in figure 3 . These simulations were hereafter designated as scenario D, T and I, respectively.

The sensitivity of model responses to variations on intersex incidence, sex ratio fluctuations, reproduction rate of intersex females and mortality rate of normal and intersex females was assessed (Table 3).

The model was written and run with Stella software version 7.0.3 (High Performance Systems, Inc.).

\section{Results}

Results indicate that E. marinus populations with male-biased sex ratios, average intersexuality incidence of $5.4 \%$ and a reproductive output rate of intersexes $12 \%$ lower than that of normal specimens show a significant decrease throughout time (Fig. 4). On the contrary, E. marinus populations with intersexuality incidence between $7.2-9.2 \%$, a reproductive output corresponding to $\sim 80 \%$ the value of normal specimens and with a preponderance of female- 
biased sex ratios show long-term persistence and with a tendency for population density increase (Fig. 4). As expected, predictions change if conditions differ. For example, in the case of scenario D, population density shows a more stable tendency, if sex ratio presents stronger seasonal fluctuations with periods where the population is female-biased (Fig. 5A). On the contrary, E. marinus population at scenario $\mathrm{T}$ starts gradually decreasing if intersexuality incidence increases to $19 \%$ or intersex reproductive output decreases to $54 \%$ the rate of normal specimens (Fig. 5B). In scenario I, E. marinus density starts decreasing when intersexuality reaches $15 \%$ of the population or intersex reproductive output decreases to $34 \%$ the rate of normal specimens (Fig. 5C). E. marinus population at scenario I is more sensitive to variations on intersexuality incidence and reproduction rate of intersexes than population at scenario $\mathrm{T}$ because the population at scenario $\mathrm{T}$ is more strongly female-biased.

Sensitivity analysis indicates that the model is very sensitive to juvenile- and normal femalerelated parameters. For instance, at scenario D, if normal female mortality decreases to $10 \%$ of the basic run value, the population density increases in the long-term even with male biased sex ratios (Fig. 6).

\section{Discussion}

In this work, we have used parameters obtained from real populations of E. marinus and incorporated them into a previously validated model, thus, the present results must be interpreted as the immediate effects of intersexuality on stable E. marinus populations without intersexuality and with average sex ratio $\sim 1$.

According to results, E. marinus populations with male-biased sex-ratios are quite sensitive to female intersexuality, even at low incidence levels, unless certain processes take place (e.g. decreased mortality rate of females), which would compensate for the lower number of females compared to males. Recently, Ford and Glazier (2008) reported a population of freshwater amphipods (Gammarus minus) with male-biased sex ratios and intersexuality. Population 
mechanisms that allow the maintenance of populations with such unusual characteristics are still unknown, but previous reports confirm the viability and stability of these populations for decades (Miller and Buikema, 1976; Buikema et al., 1980), thus, it seems that male-biased sex ratios and intersexuality may co-exist in viable populations.

The present results also indicate that sex ratio fluctuations, which cause the population to be female-biased during certain periods of the year, can counteract the decreasing tendency observed in the population at scenario D. It is well known that environmental parameters, such as temperature and photoperiod can control the sex ratio in some species of amphipods (Watt and Adams, 1993; Naylor et al., 1998; Dunn et al., 2005). In the case of E. marinus populations monthly and yearly sex ratio fluctuations are frequently observed (Vlasblom, 1969). This indicates that, at least in certain periods, sex ratio variation can favour females in amphipod populations.

The present results also indicate that intersexed female-biased populations of E. marinus are viable and can even exhibit an increasing density tendency for moderate intersex incidence $(<14 \%)$ and if the reproduction rate of intersex females is not considerably lower than that of normal females (not lower than 54\%). According to results, more strongly female-biased populations are less sensitive to increases on intersexuality incidence or decreases on the reproduction rate of intersexes. In general, intersex populations of E. marinus tend to be femalebiased, which seems to be caused by microsporodian parasites that can be simultaneously the cause of intersexuality and female-biased sex ratios in certain populations (Ford et al., 2006). It is expected that, above a certain threshold, sex ratio distortion leads to population extinction. In cases of female-biased populations, if males become too rare to maintain the population through reproduction, the populations will collapse (Hatcher et al., 1999). In the future, it would be useful to determine the minimum male to female ratio which allows viable populations of $E$. marines and include it in population models. 
Besides sex ratio, the reproduction rate of intersex females is another process affecting the maintenance of intersexed populations. If the output rate of intersex females is much lower than that of normal females, then the populations will be more sensitive to intersexuality even if the sex ratio remains female-biased. Apparently, in some species, intersex females do not present a lower fecundity rate than normal females (Ladewig et al., 2007). However, this is not the case of E. marinus, where the reproductive rate of intersexed females is significantly lower than the rate of normal females (20\% on average), particularly, in more polluted and impacted sites (Ford et al., 2003; 2004b). Thus, although a general cause-effect between pollution and intersexuality has not been established (Ford et al., 2006), intersexed populations of E. marinus from polluted sites may be at a higher risk due to lower reproduction rates of both of normal and intersex females among other factors (Ford et al., 2003).

The present simulations corroborate, in general, the simulations of our previous theoretical approach (Ford et al., 2007) but they have brought more understanding to, at least, some of the underlying processes which seem to occur in intersexed populations and to regulate their variation.

Overall, the present results indicate that the survivorship of intersexed populations of E. marinus will not depend only on the incidence level of intersexuality but instead it seems to be regulated by a set of different factors, whereby the incidence of intersexuality, sex ratio and reproduction rate of intersexes seem to play important roles.

In highlighting the sensitivity of amphipod populations to changes in sex ratios, fecundity and the incidence of intersexuality, the model also emphasises the potential effect changes in the climate and that of pollutants could have on population dynamics with plasticity in their sex determination. The speed that populations respond genetically may ultimately dictate how populations can adapt to anthropogenic changes in their environment. 


\section{Acknowledgements}

This work was funded by CRUP - The Board of Rectors from Portuguese Universities, by the British Council within the Treaty of Windsor Anglo-Portuguese Joint Research Programme (AIB/05), IMAR - The Institute of Marine Research, Coimbra Interdisciplinary Centre and by Napier University, UK.

\section{References}

Buikema, A.L., Chester, A.L., Stevens, H.R., 1980. Intersexuality in Gammarus minus Say. Crustaceana 6 (Suppl.): 111-117

Charnov, E.L., 1982. The theory of sex allocation. Princeton University Press, New Jersey, 355 pp.

Dunn, A.M., McCabe, M.J., Adams, J., 1996. Intersexuality in Gammarus duebeni (Amphipoda), a cost incurred in populations with environmental sex determination? Crustaceana 9: 313-320

Dunn, A.; Hogg, J.C.; Kelly, A.; Hatcher, M.J., 2005. Two cues for sex determination in Gammarus duebeni: Adaptive variation in environmental sex determination? Limnology and Oceanography 50, pp.346 - 353

Ford, A.T., Fernandes, T.F., Rider, S.A., Read, P.A., Robinson, C.D., Davies, I.M., 2003. Reproduction in the amphipod, Echinogammarus marinus: a comparison between normal and intersex specimens. Journal of the Marine Biological Association of the UK 83: 937940

Ford, A.T., 2004. Endocrine disruption and intersexuality in the amphipod, Echinogammarus marinus. Napier University Edinburgh, Scotland, UK

Ford, A.T., Fernandes, T.F., Read, P.A., Robinson, C.D., Davies, I.M., 2004. The costs of intersexuality: A crustacean perspective. Marine Biology 145: 951-957 
Ford, A.T., Fernandes, T.F., Read, P.A., Robinson, C.D., Davies I.M., 2006. Can pollution cause intersexuality in the amphipod, Echinogammarus marinus? Marine Pollution Bulletin 53: $100-106$

Ford, A.T., Martins, I., Fernandes, T.F., 2007. Population level effects of intersexuality in the marine environment. Science of the Total Environment 374: 102-111

Hatcher M.J., Taneyhill, D.E., Dunn, A.M., Tofts, C., 1999. Population dynamics under parasitic sex ratio distortion. Theoretical Population Biology 56: 11-28

Jobling, S., Coey, S., Whitmore, J.G., Kime, D.E., Van Look, K.J.N., McAllister, B.G., Beresford, N., Henshaw, A.C., Brighty, G., Tyler, C.R., Sumpter, J.P., 2002. Wild intersex roach (Rutilus rutilus) have reduced fertility. Biology of Reproduction 67: 515-524

Jørgensen, S.E., 1994. Fundamentals of Ecological Modelling, $2^{\text {nd }}$ Edition, Elsevier, Amsterdam, p. 628

Kelly, A., Dunn, A. M., Hatcher, M. J., 2002. Incomplete feminisation by the microsporidian sex ratio distorter, Nosema granulosis, and reduced transmission and feminisation efficiency at low temperatures. International Journal of Parasitology 32: 825-831

Kelly, A., Hatcher, M., Dunn, A., 2004. Intersexuality in the amphipod Gammarus duebeni results from incomplete feminisation by the vertically transmitted parasitic sex ratio distorter Nosema granulosis. Evolutionary Ecology 18: 121-132

Ladewig, V., Jungmann, D., Petzsch, P., Pitsch, M., Stäglich, I., Nagel, R., 2007. Does intersexuality affect precopula and fecundity in Gammarus fossarum (Crustacea: Amphipoda)? Arch. Hydrobiol. 168: 201-210

Miller, J.D., Buikema Jr., A.L., 1976. Observations on the ecology of the spring form of Gammarus minus (Form III) Say. Crustaceana 4 (Suppl.): 153-163

Maranhão, P., Bengala, N., Pardal, M., Marques, J.C., 2001. The influence of environmental factors on the population dynamics, reproductive biology and productivity of 
Echinogammarus marinus Leach (Amphipoda, Gammaridae) in the Mondego estuary (Portugal). Acta Oecol. 22, 139-152

Maranhão, P., Marques, J.C., 2003. The influence of temperature and salinity on the duration of embryonic development, fecundity and growth of the amphipod Echinogammarus marinus Leach (Gammaridae). Acta Oecologica 24: 5-13

Martins, I., Maranhão P., Marques, J.C., 2002. Modelling the effects of salinity variation on Echinogammarus marinus Leach (Amphipoda, Gammaridae) density and biomass in the Mondego estuary (Western Portugal). Ecological Modelling 153: 247-260

Naylor, C., Adams, J., Greenwood, P., 1988. Population dynamics and adaptive sexual strategies in a brackish water crustacean, Gammarus duebeni. Journal of Animal Ecology 57: 24932507

Olmstead AW, LeBlanc GA. 2007. The Environmental-Endocrine Basis of Gynandromorphism (Intersex) in a Crustacean. Int J Biol Sci; 3:77-84

Takahashi T, Araki A, Nomura Y, Koga M, Arizono K (2000) The occurrence of dual-gender imposex in Japanese freshwater crab. J Health Sci 46:376-379

Vlasblom, A.G., 1969. A study of a population of Marinogammarus marinus (Leach) in the Oosterschelde. Netherlands Journal of Sea Research. 4(3), 317-338

Von Bertalanffy, L., 1957. Quantitative laws in metabolism and growth. The Quarterly Review of Biology, 32 (3): 217-231

Watt, P.J., Adams., 1993. Adaptive sex determination and population dynamics in a brackishwater amphipod. Estuarine, Coastal and Shelf Science, 37, 237-250 
Figure 1- Simplified conceptual diagram of the model. The model has 5 state variables: Juveniles, males, immature females, adult females and intersex females expressed as individuals $\mathrm{m}^{-2}$ (ind $\mathrm{m}^{-2}$ ). $m_{1,2,3,4,5^{-}}$mortality rates; $t_{1,2,3,4^{-}}$flow rates of individuals between groups; $r a-$ reproduction rate of adult females; ri- reproduction rate of intersex females. Rate units correspond to ind $\mathrm{m}^{-2} \mathrm{~d}^{-1}$. The dash line indicates that $r i$ is calculated as a proportion of $r a$ according to Ford (2004). Temperature and salinity are the forcing functions that regulate reproduction and growth (not shown).

Figure 2- Observed variation of intersexuality incidence (A) and sex ratio (B) of Echinogammarus marinus populations at study sites: Dunbar $(\bullet)$, Torry Bay $(\bigcirc)$ and Inverkeithing Bay ( $\mathbf{\nabla}$ ) during Spring and Summer 2002, Winter and Spring 2003.

Figure 3- Imposed variation of intersexuality incidence (A) and sex ratio (B) at scenario D (solid), T (dotted) and I (dash)

Figure 4- Long-term variation of Echinogammarus marinus density (ind $\mathrm{m}^{-2}$ ) at scenario D (solid), T (dotted) and I (dash)

Figure 5- Long-term variation of Echinogammarus marinus density (ind $\mathrm{m}^{-2}$ ) at the three scenarios under different conditions. A- Scenario D with sex ratio fluctuations (solid line), population density (dash line), B- Scenario $\mathrm{T}$ with higher intersexuality (solid line) or low reproduction output of intersexes (dash line), C- Scenario I with higher intersexuality (solid line) or low reproduction output of intersexes (dash line). 
Figure 6- Long-term variation of Echinogammarus marinus density at scenario D (dash line)

1 with male biased sex ratios (solid line) and lower mortality rate of normal adult females. In these circumstances, the population exhibits long-term stability. 


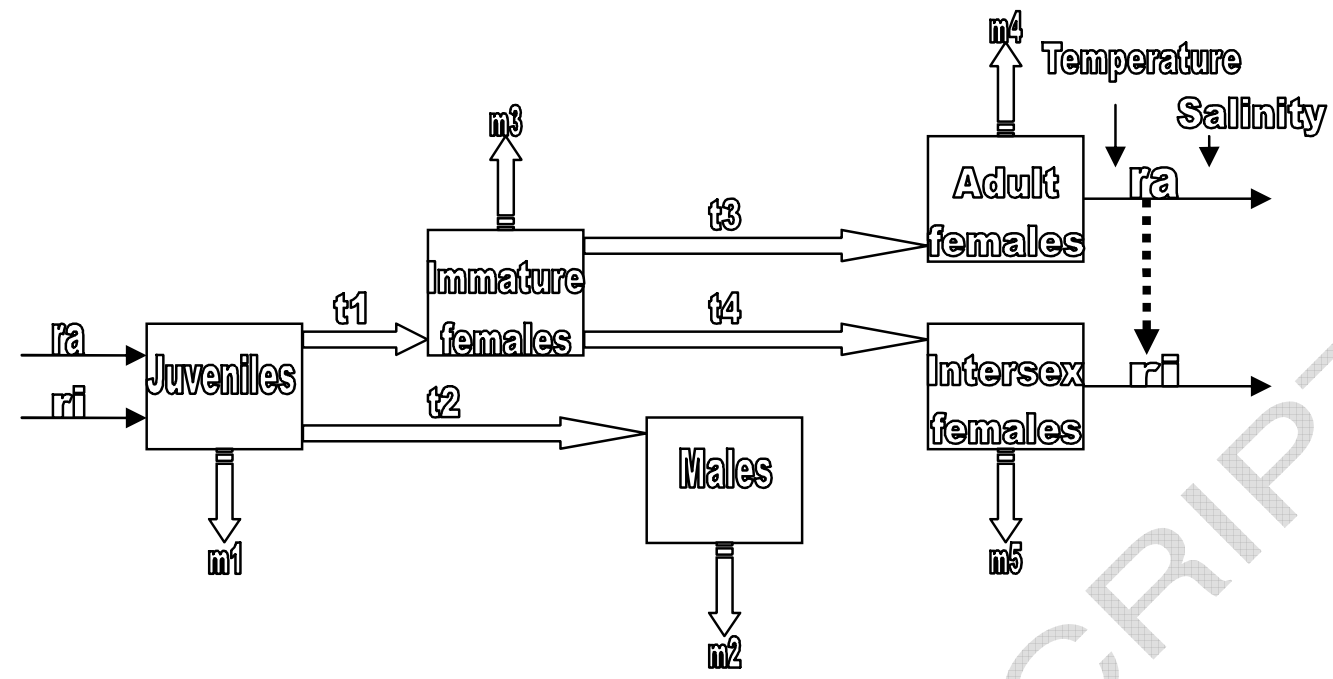

Figure 1 
Figure 2
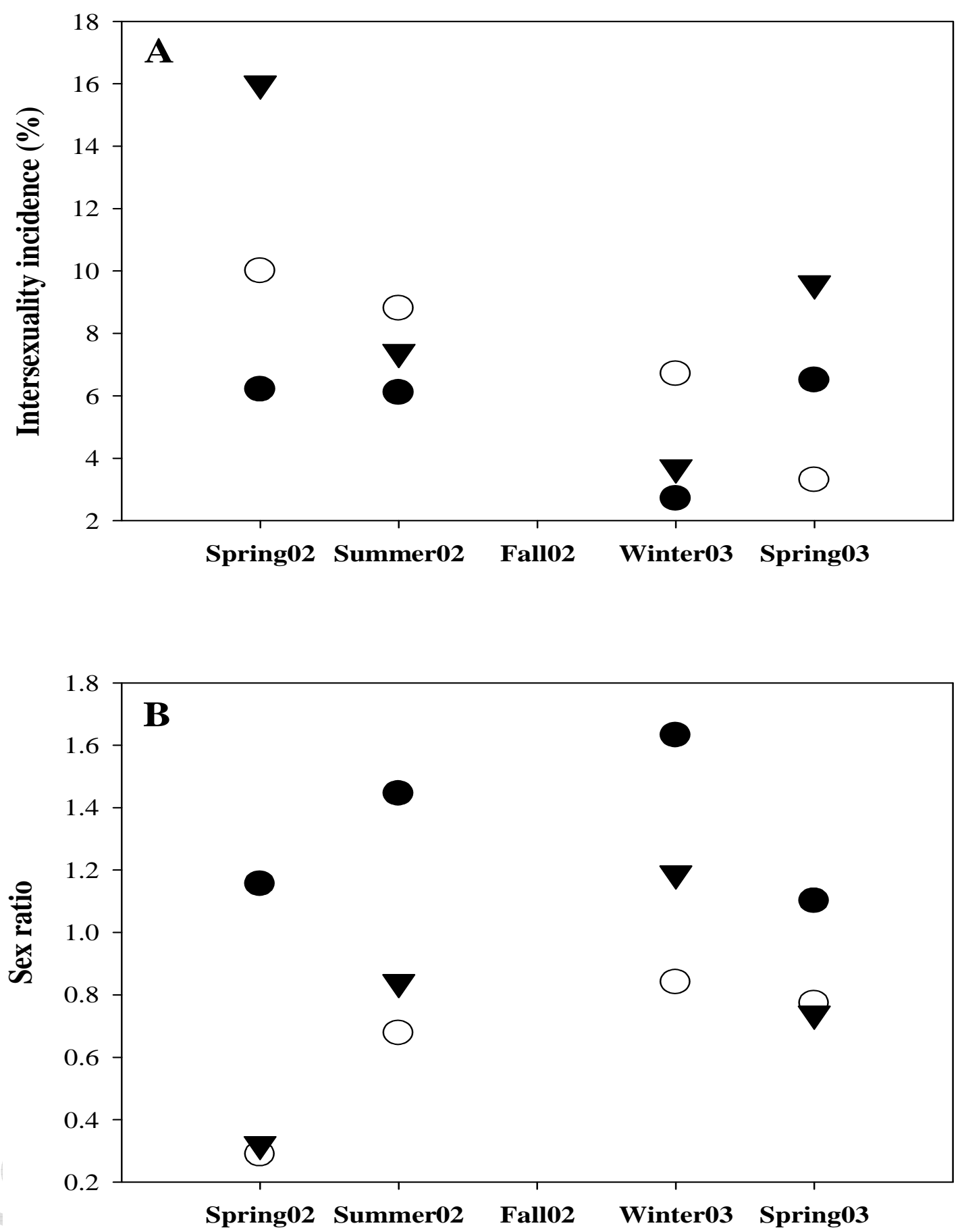
Figure 3
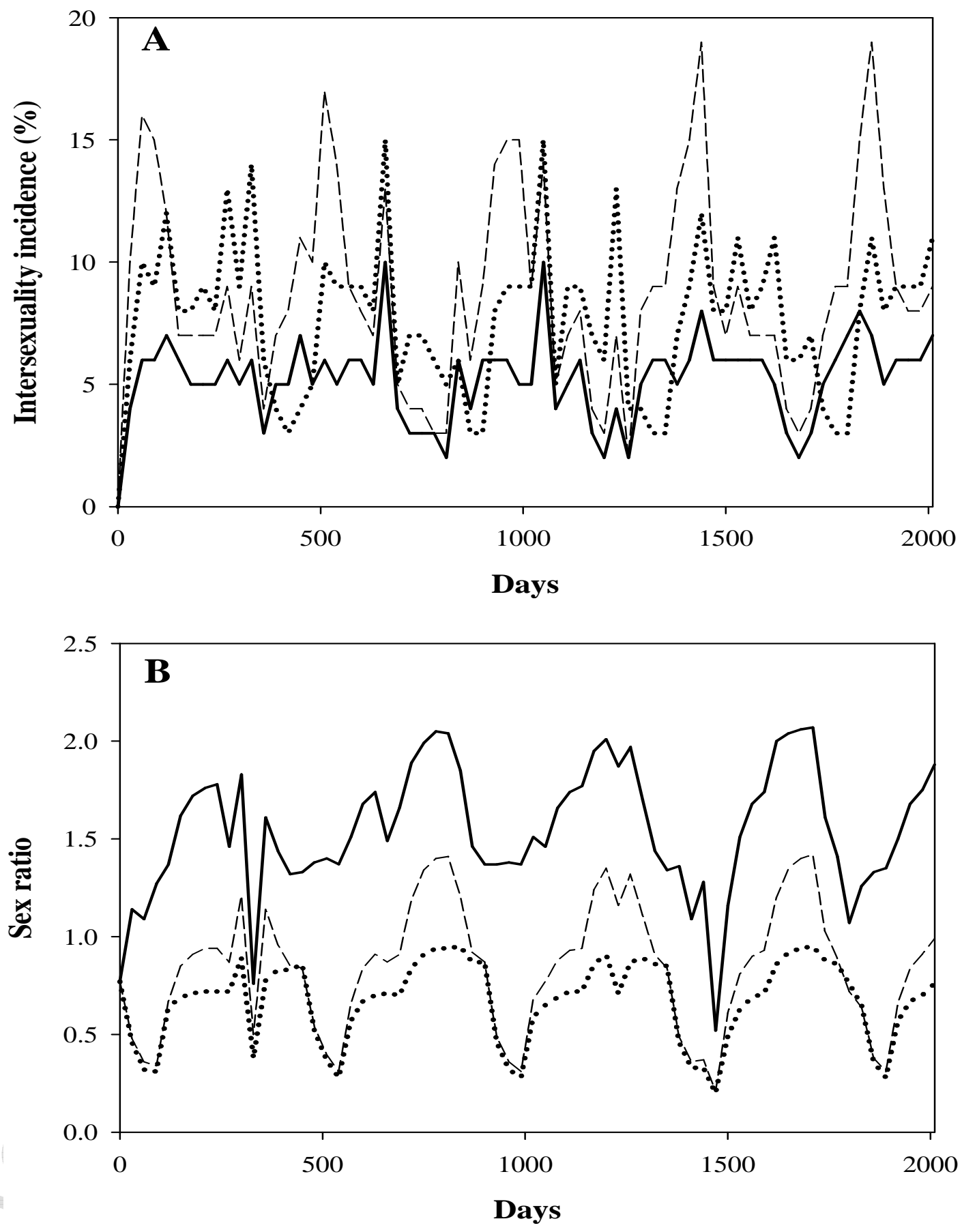
Figure 4

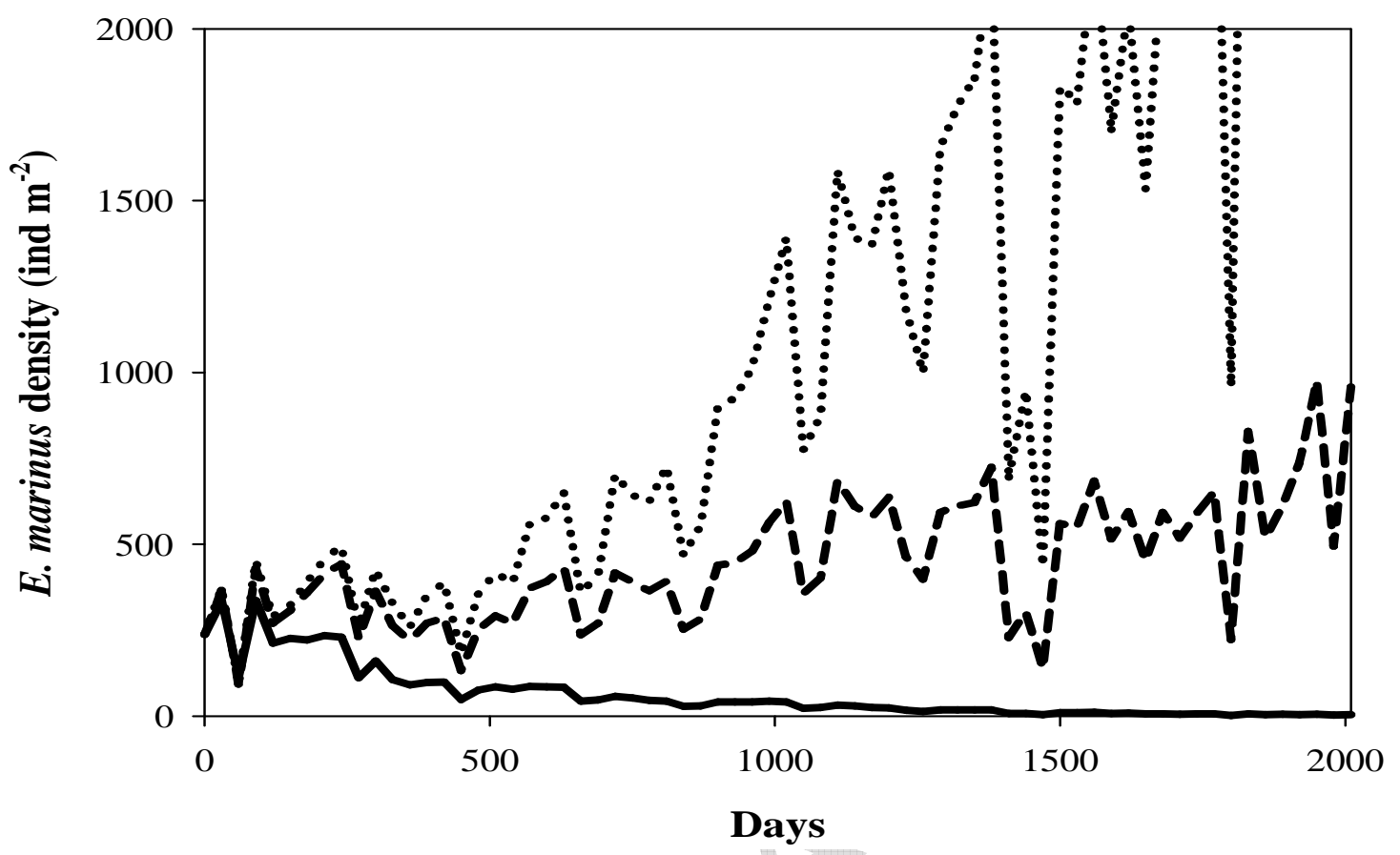


Figure 5
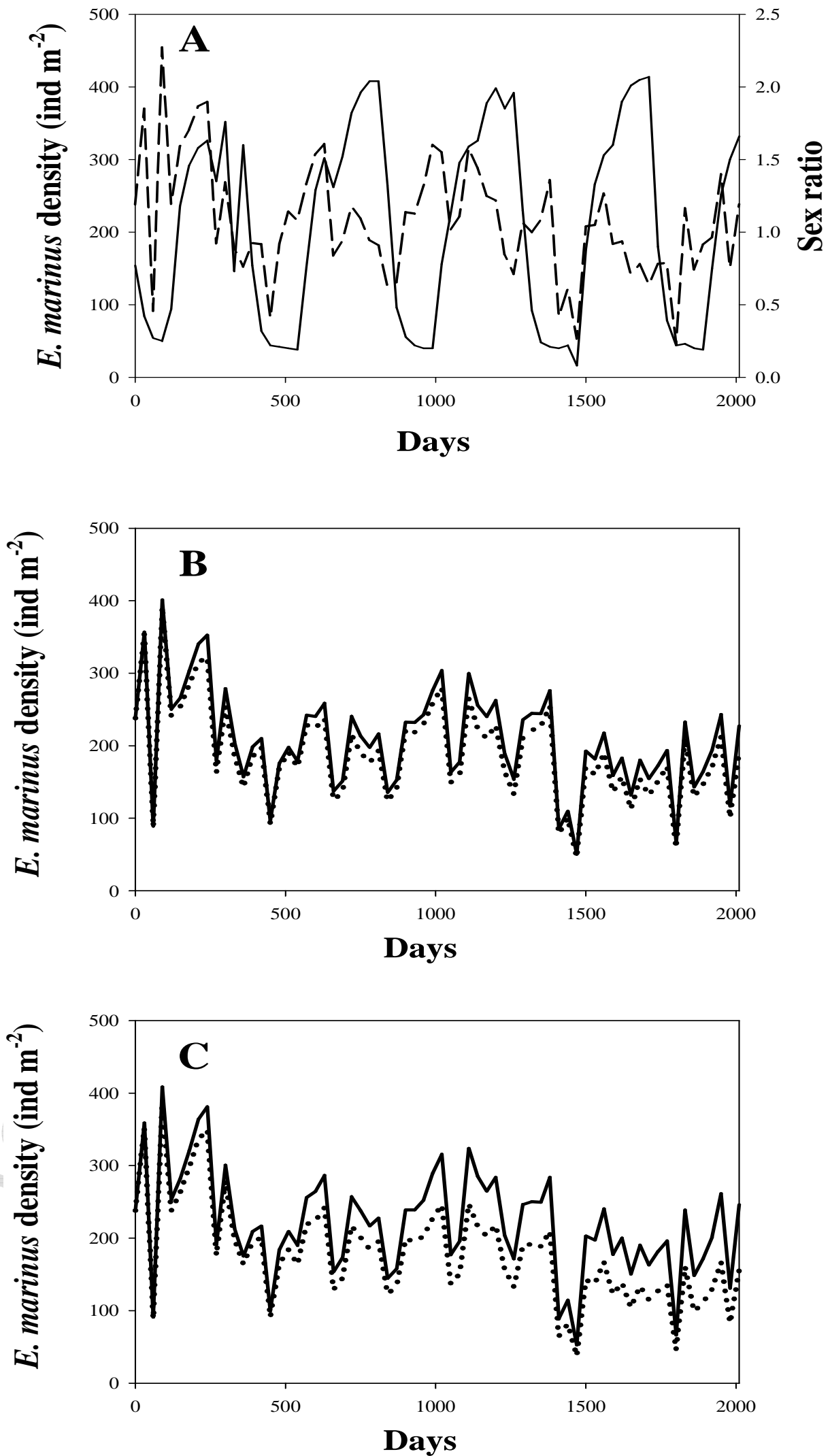
Figure 6

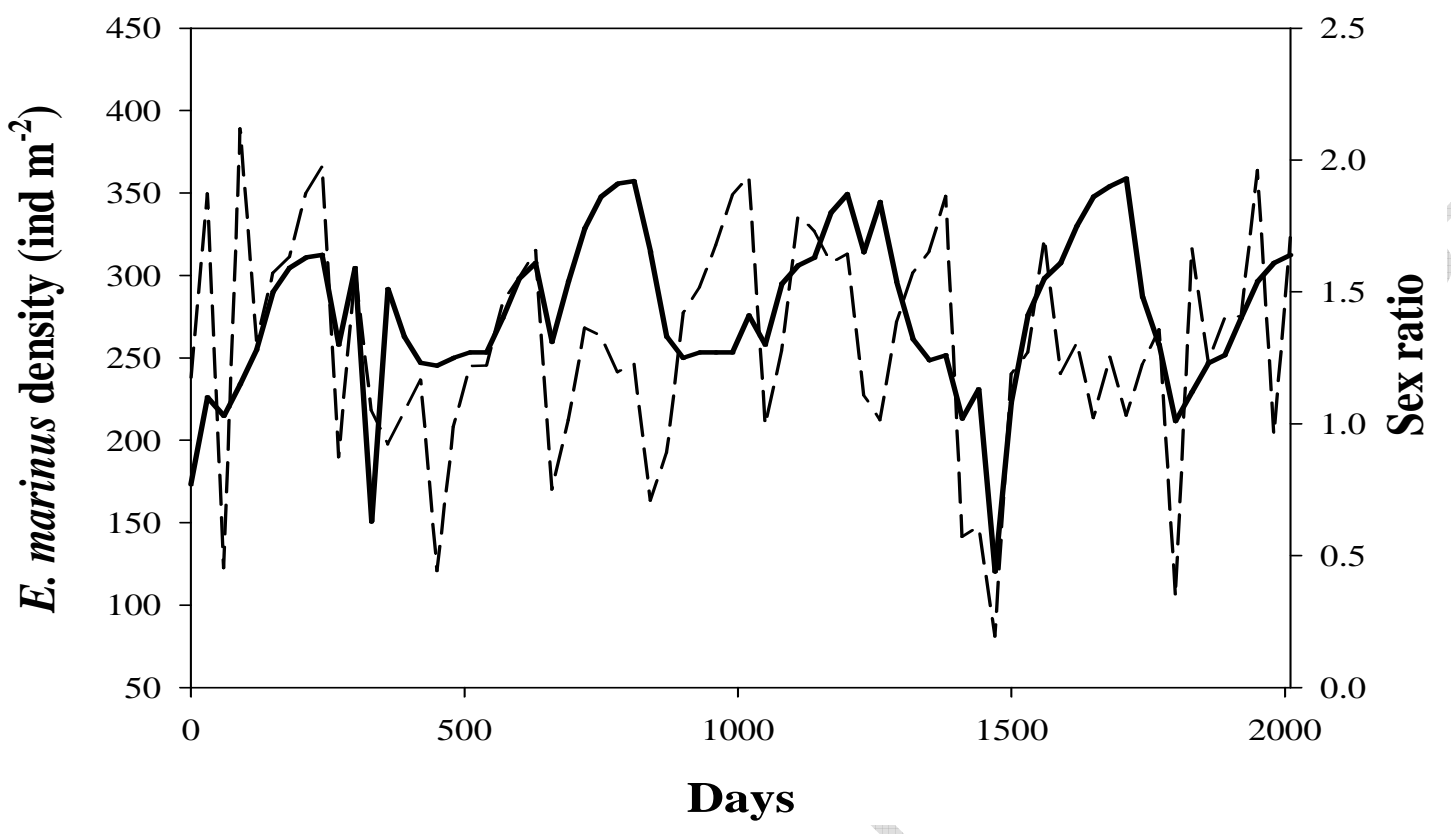


Table 1- Main equations of the model. Juv- juveniles, FIm- immature females, FA- adult females, FInt- intersex females, Male- males, R- recruitment, mort- mortality, t- transfer of individuals from one population group to the next, $\mathrm{AvW}$ - average weight, $\mathrm{W}_{\mathrm{i}-1^{-}}$weight at the beginning of the population group $\mathrm{i}, \mathrm{W}_{\mathrm{i}^{-}}$weight at the end of population group $\mathrm{i}$, days $\mathrm{i}_{\mathrm{i}-1, \mathrm{i}^{-}}$ average duration of a certain population group, W- weight, CL- cephalic length, h- anabolism parameter, $\mathrm{k}$ - catabolism parameter, $\mathrm{f}(\mathrm{T})$ - temperature factor, $\mathrm{t}$ - time (for a better explanation of the biomass calculation module see Martins et al., 2002).

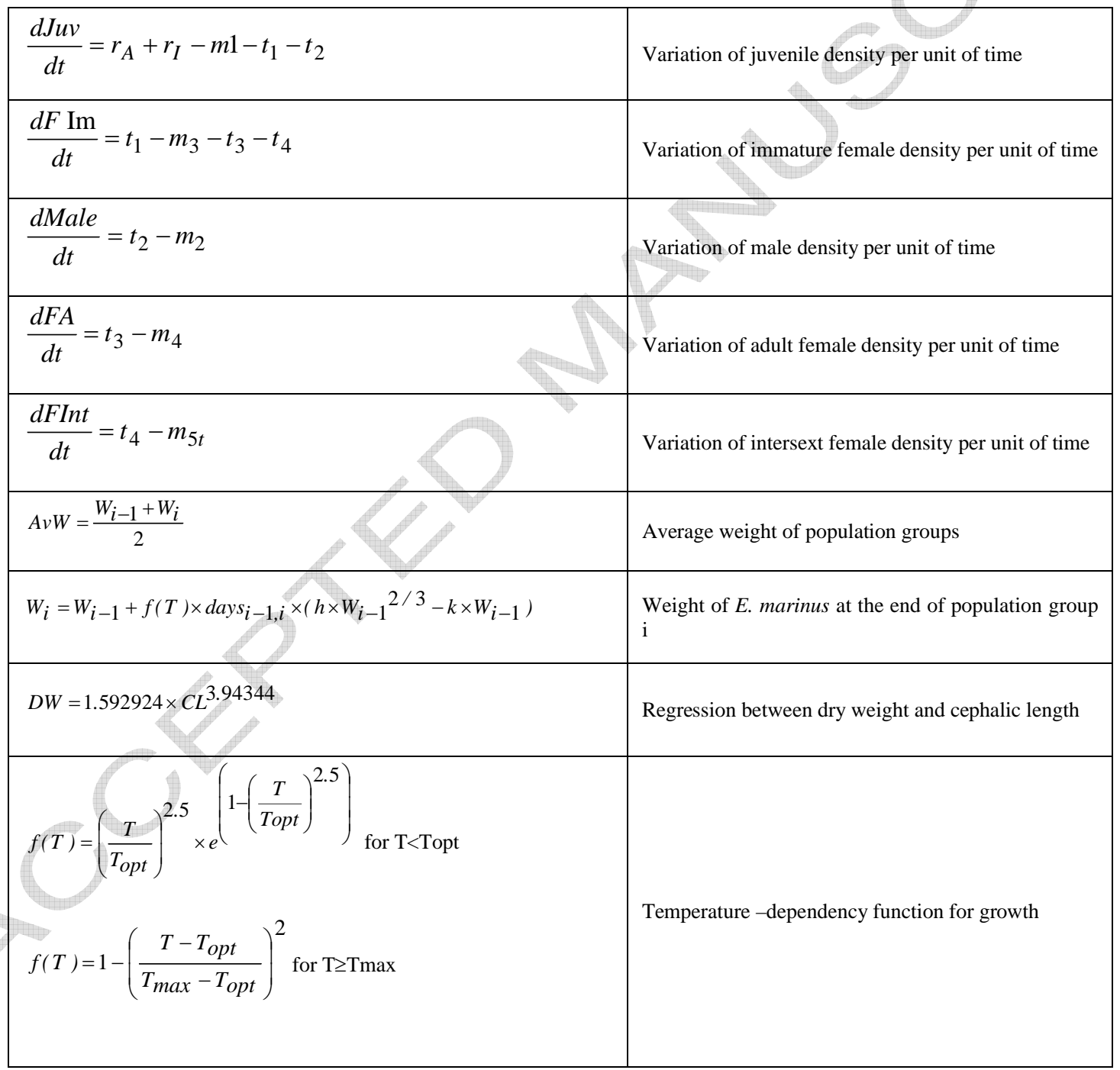




\begin{tabular}{|c|c|}
\hline $\begin{array}{l}N B J=0 \text { for salinity } \leq 4 \\
N B J=-70.3+62.8 \times C L_{F A} \text { for temp. }<15 \\
N B J=-50.4+44.8 \times C L_{F A} \text { for temp. } \geq 15 \text { and }<23 \\
N B J=-11.7+12.2 \times C L_{F A} \text { for temp. } \geq 23\end{array}$ & $\begin{array}{l}\text { Number of new-born juveniles as a function of } \\
\text { salinity, temperature and normal adult female's } \\
\text { cephalic length }\end{array}$ \\
\hline$r_{a}=N B J \times 0.0291 \times F A$ & Reproduction rate of adult females \\
\hline $\begin{array}{l}r_{i}=N B J \times 0.025637 \times \text { FInt } \text { for Dunbar } \\
r_{i}=N B J \times 0.022814 \times \text { FInt } \text { for Torry } \\
r_{i}=N B J \times 0.023629 \times \text { FInt } \text { for Inverkeithing }\end{array}$ & $\begin{array}{l}\text { Reproduction rate of intersex females at the three } \\
\text { sites calculated according to a } \% \text { of decrease } \\
\text { relatively to } 0.0291\end{array}$ \\
\hline$m_{i}=m_{i} \times D_{i}$ & $\begin{array}{l}\text { Mortality rate of spopulation groups }{ }_{i} \text { as a function of } \\
\text { density }\end{array}$ \\
\hline
\end{tabular}


Table 2 - Observed and simulated phenotype variation (\%) for E. marinus populations at the three studied sites and during the study periods. Observed values were obtained by Ford et al. (2006). Simulated values were obtained after re-calibration of the model (see text for explanation).

\begin{tabular}{|c|c|c|c|}
\hline Sites/season & Phenotypes & Observed & Simulated \\
\hline \multirow[t]{3}{*}{ Dunbar - Spring 2002} & male & 53.6 & 53.6 \\
\hline & normal female & 40.2 & 40.3 \\
\hline & intersex female & 6.2 & 6.1 \\
\hline \multirow[t]{3}{*}{ Summer 2002} & male & 59.1 & 59.1 \\
\hline & normal female & 34.8 & 34.9 \\
\hline & intersex female & 6.1 & 6.1 \\
\hline \multirow[t]{3}{*}{ Winter 2002/03 } & male & 62 & 62.1 \\
\hline & normal female & 35.3 & 35.3 \\
\hline & intersex female & 2.7 & 2.7 \\
\hline \multirow[t]{3}{*}{ Spring 2003} & male & 52.4 & 52.2 \\
\hline & normal female & 41.1 & 41.3 \\
\hline & intersex female & 6.5 & 6.5 \\
\hline \multirow[t]{3}{*}{ Torry Bay - Spring 2002} & male & 22.4 & 22.2 \\
\hline & normal female & 67.7 & 67.8 \\
\hline & intersex female & 10 & 10.0 \\
\hline \multirow[t]{3}{*}{ Summer 2002} & male & 40.3 & 40.3 \\
\hline & normal female & 50.7 & 50.9 \\
\hline & intersex female & 8.8 & 8.8 \\
\hline \multirow[t]{3}{*}{ Winter 2002/03 } & male & 45.7 & 45.8 \\
\hline & normal female & 47.7 & 47.7 \\
\hline & intersex female & 6.7 & 6.5 \\
\hline \multirow[t]{3}{*}{ Spring 2003} & male & 43.6 & 43.6 \\
\hline & normal female & 53.1 & 53.1 \\
\hline & intersex female & 3.3 & 3.3 \\
\hline \multirow{3}{*}{ Inverkeithing Bay - Spring 2002} & male & 24.3 & 23.9 \\
\hline & normal female & 59.7 & 60.1 \\
\hline & intersex female & 16 & 16.1 \\
\hline Summer 2002 & male & 45.7 & 45.9 \\
\hline 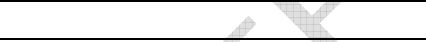 & normal female & 47 & 46.8 \\
\hline 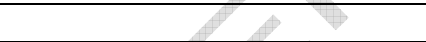 & intersex female & 7.4 & 7.4 \\
\hline Winter $2002 / 03$ & male & 54.3 & 54.4 \\
\hline 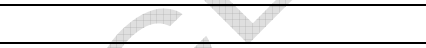 & normal female & 42 & 41.9 \\
\hline & intersex female & 3.7 & 3.7 \\
\hline Spring 2003 & male & 42.5 & 42.5 \\
\hline 4 & normal female & 47.9 & 47.9 \\
\hline 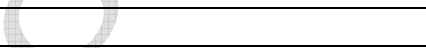 & intersex female & 9.6 & 9.6 \\
\hline
\end{tabular}


Table 3 - Sensitivity (sensu Jørgensen, 1994) of the population density to $\pm 10 \%$ variations on mortality parameters at the three considered scenarios. m1- juvenile mortality, m2- male mortality, m3- immature female mortality, m4- adult female mortality and m5- intersex female mortality.

\begin{tabular}{|c|c|c|c|c|}
\hline Parameter & Variation & $\begin{array}{c}\text { Sensitivity } \\
\text { Scenario D }\end{array}$ & $\begin{array}{c}\text { Sensitivity } \\
\text { Scenario T }\end{array}$ & $\begin{array}{c}\text { Sensitivity } \\
\text { Scenario I }\end{array}$ \\
\hline $\mathrm{m} 1$ & $+10 \%$ & -2.2 & -3.2 & -3.0 \\
\hline & $-10 \%$ & +2.0 & +2.8 & +2.7 \\
\hline $\mathrm{m} 2$ & $+10 \%$ & -0.2 & -0.1 & -0.1 \\
\hline & $-10 \%$ & +0.3 & +0.1 & +0.2 \\
\hline $\mathrm{m} 3$ & $+10 \%$ & -1.2 & -1.5 & -1.5 \\
\hline & $-10 \%$ & +1.2 & +1.4 & +1.4 \\
\hline $\mathrm{m} 4$ & $+10 \%$ & -1.9 & -2.7 & -2.3 \\
\hline & $-10 \%$ & +1.8 & +2.3 & +2.1 \\
\hline $\mathrm{m} 5$ & $+10 \%$ & -0.6 & -0.7 & -0.8 \\
\hline & $-10 \%$ & +0.7 & +0.7 & +0.9 \\
\hline
\end{tabular}

